\title{
Will Regenerative Medicine Replace Transplantation?
}

\author{
Giuseppe Orlando ${ }^{1,2}$, Shay Soker ${ }^{2}$, Robert J. Stratta ${ }^{1}$, and Anthony Atala ${ }^{1}$ \\ ${ }^{1}$ Department of General Surgery, Section of Transplantation, Wake Forest School of Medicine, \\ Winston Salem, North Carolina 27157 \\ ${ }^{2}$ Wake Forest Institute for Regenerative Medicine, Wake Forest School of Medicine, Winston Salem, \\ North Carolina 27157 \\ Correspondence: gorlando@wakehealth.edu
}

\begin{abstract}
Recent groundbreaking advances in organ bioengineering and regeneration have provided evidence that regenerative medicine holds promise to dramatically improve the approach to organ transplantation. The two fields, however, share a common heritage. Alexis Carrel can be considered the father of both regenerative medicine and organ transplantation, and it is now clear that his legacy is equally applicable for the present and future generations of transplant and regenerative medicine investigators. In this review, we will briefly illustrate the interplay that should be established between these two complementary disciplines of health sciences. Although regenerative medicine has shown to the transplant field its potential, transplantation is destined to align with regenerative medicine and foster further progress probably more than either discipline alone. Organ bioengineering and regeneration technologies hold the promise to meet at the same time the two most urgent needs in organ transplantation, namely, the identification of a new, potentially inexhaustible source of organs and immunosuppression-free transplantation of tissues and organs.
\end{abstract}

$\mathrm{O}$ rgan transplantation and regenerative medicine share the same heritage. Alexis Carrel is considered the father of transplant (and vascular) surgery, however, his seminal studies on cell culture and ex vivo organ preservation and growth anticipated organ bioengineering and regeneration concepts were not developed until decades later (Orlando et al. 2011b). Carrel's visionary investigations, the majority of which were performed in collaboration with engineer and celebrated aviator Charles Lindbergh, established the foundation of modern regenerative medicine. Notably, Carrel and Lindbergh's per- fusion pump may be referred to as one of the greatest inventions in health sciences in the twentieth century. That machine, by allowing living organs to exist outside of the body during surgery, was a crucial step in the development of perfusion systems for cardiac and transplant surgery, as well as for any sort of device requiring extracorporeal circulation. Moreover, the perfusion pump may also be considered the precursor of the bioreactors commonly used nowadays in tissue and organ bioengineering, which are sealed mechanical chambers designed to provide appropriate environmental conditions

Editors: Laurence A. Turka and Kathryn J. Wood

Additional Perspectives on Transplantation available at www.perspectivesinmedicine.org

Copyright (C) 2013 Cold Spring Harbor Laboratory Press; all rights reserved; doi: 10.1101/cshperspect.a015693

Cite this article as Cold Spring Harb Perspect Med 2013;3:a015693 
G. Orlando et al.

for cellular activity and welfare (Badylak et al. 2012). Carrel's pioneering developments on both fronts of organ transplantation and regenerative medicine occurred decades before either became clinical realities, and almost a century before the successful implantation in patients of bioengineered tissues or organs (Romagnoli et al. 1990; Pellegrini et al. 1997; Quarto et al. 2001; Shinoka et al. 2001; Warnke et al. 2004; Atala et al. 2006; Macchiarini et al. 2008; McAllister et al. 2009; Mertsching et al. 2009; Baiguera et al. 2010; Hibino et al. 2010; Rama et al. 2010; Junglebuth et al. 2011; Elliott et al. 2012; Olausson et al. 2012), or the early attempts to bioengineer more complex organs for transplant purposes (Ott et al. 2008, 2010; Ross et al. 2009; Petersen et al. 2010; Uygun et al. 2010; Wainwright et al. 2010; Baptista et al. 2011; Hammond et al. 2011; Soto-Gutierrez 2011; Barakat et al. 2012; Hata et al. 2012; Orlando et al. 2012a; Yagi et al. 2012).

\section{THE URGENT NEED FOR NEW SOURCES OF TRANSPLANTABLE ORGANS}

Organ transplantation may be referred to as one of the greatest achievements in the history of medicine. Short-, medium-, and long-term results are excellent and, when compared with patients who cannot receive a new organ, the impact on a patient's mortality, morbidity, and quality of life is tremendous. If we consider kidney transplantation as a paradigmatic example, it currently represents the gold standard for renal replacement therapy in patients affected by endstage renal disease. In fact, when compared with maintenance peritoneal or hemodialysis, renal transplantation dramatically improves patient survival, quality of life, and is cost effective in terms of health care expenditures. According to a recent U.S. Renal Data System report, life expectancy from the time renal dialysis is initiated is approximately 8 years for patients between the ages of 40 and 44 , and 4.5 years for those who are between 60 and 64 years of age (www.usrds.org). These figures are far surpassed by the increased survival rates following kidney transplantation, which are $85 \%, 70 \%$, and $44 \%$ after 5, 10, and 20 years, respectively (information based on the Organ Procurement and
Transplantation Network data as of July 27, 2012 [optn.transplant.hrsa.gov]) (Table 1). Similar data are reported by the European Renal Association-European Dialysis and Transplant Association (ERA-EDTA) Registry (www.eraedta-reg.org/files/annualreports/pdf/AnnRep 2010.pdf), for which expected remaining lifetimes in years of dialysis versus transplant patients in the year ranges of 40-44 and 60-64 are 10.7 versus 27 years, and 5.7 versus 13.4, respectively. A consequence of the effectiveness of renal transplantation as renal replacement treatment is that, indications for kidney transplantation have expanded considerably in terms of recipient age, primary disease leading to end-stage renal failure, and degree of deterioration in clinical condition at the time of transplantation. In other words, we are now placing on the waiting listand eventually transplanting — patients who are older and sicker than in earlier times, and are affected by diseases that years ago would have represented a contraindication for transplantation.

As a corollary, transplant waiting lists are rapidly increasing but, unfortunately, the numerous strategies that are currently being implemented to expand the donor organ pool are not keeping pace with the demand (Fig. 1). Some of these measures include expansion of living and deceased donor acceptance criteria such as use of organs from expanded criteria donors or donors after cardiac death, transplants across immunological barriers, paired donations, Good Samaritan or altruistic donations, etc., and have been very well discussed in other articles in this collection. Although the gap between increasing demand and supply of organs is dramatically widening, the cumulative probability to receive an organ in the critical time frame is dropping drastically and mortality on the waiting list is fearfully increasing (www.medscape.org/viewarticle/488926) (Table 2). At the end of 2011, 96,574 patients were waiting for a kidney in the United States, whereas only 16,813 kidney transplants were performed during the calendar year (optn.transplant.hrsa.gov). This corresponds to a cumulative probability to receive a renal graft at 1 year (from the time of registration on the waiting list) of only $9.65 \%$. This figure increases at 
Table 1. Actuarial patient survival rates after kidney transplant (KT)

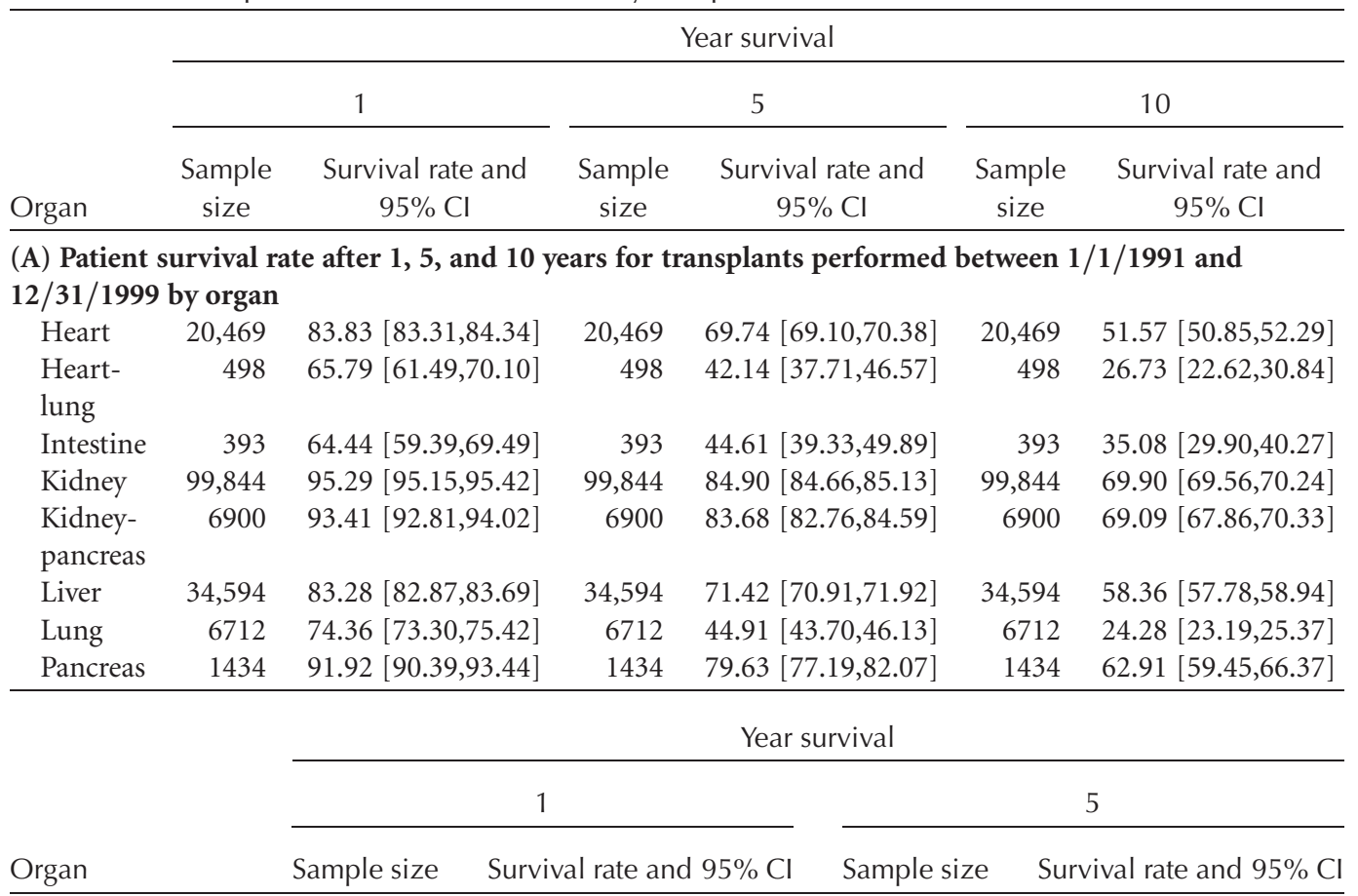

(B) Patient survival rate after 1 and 5 years for transplants performed between $1 / 1 / 2000$ and $12 / 31 / 2005$ by organ

\begin{tabular}{|c|c|c|c|c|}
\hline Heart & 12,753 & $86.78[86.18,87.38]$ & 12,753 & $73.74[72.96,74.52]$ \\
\hline Heart-lung & 212 & $68.42[61.80,75.04]$ & 212 & $47.92[41.00,54.84]$ \\
\hline Intestine & 748 & $76.60[73.42,79.79]$ & 748 & $56.75[52.99,60.51]$ \\
\hline Kidney & 90,309 & $95.69[95.56,95.83]$ & 90,309 & $85.41[85.17,85.66]$ \\
\hline Kidney-pancreas & 5367 & $94.73[94.11,95.35]$ & 5367 & $86.11[85.13,87.09]$ \\
\hline Liver & 33,816 & $86.14[85.76,86.52]$ & 33,816 & $72.92[72.42,73.42]$ \\
\hline Lung & 6723 & $81.35[80.40,82.29]$ & 6723 & $53.09[51.87,54.31]$ \\
\hline Pancreas & 3116 & $94.64[93.79,95.48]$ & 3116 & $83.00[81.49,84.51]$ \\
\hline & & \multicolumn{3}{|c|}{ Year survival } \\
\hline & & \multicolumn{3}{|c|}{20} \\
\hline \multicolumn{2}{|l|}{ Organ } & Sample size & & Survival rate and $95 \%$ \\
\hline \multicolumn{5}{|c|}{$\begin{array}{l}\text { (C) Patient survival rate after } 20 \text { years for transplants performed between 10/01/1987 and 12/31/1990 } \\
\text { organ }\end{array}$} \\
\hline \multicolumn{2}{|l|}{ Heart } & 5843 & & $18.45[17.29,19.61]$ \\
\hline \multicolumn{2}{|l|}{ Heart-lung } & 202 & & $14.16[8.35,19.98]$ \\
\hline \multicolumn{2}{|l|}{ Kidney } & 28,987 & & $43.69[42.74,44.64]$ \\
\hline \multicolumn{2}{|l|}{ Kidney-pancreas } & 993 & & $38.41[34.37,42.45]$ \\
\hline \multicolumn{2}{|l|}{ Liver } & 6926 & & $33.95[32.51,35.40]$ \\
\hline \multicolumn{2}{|l|}{ Pancreas } & 238 & & $24.71[15.03,34.39]$ \\
\hline
\end{tabular}

Data are stratified by year of transplantation (based on open access, official data from Organ Procurement and Transplantation Network data as of July 27, 2012).

CI, confidence interval. 
G. Orlando et al.
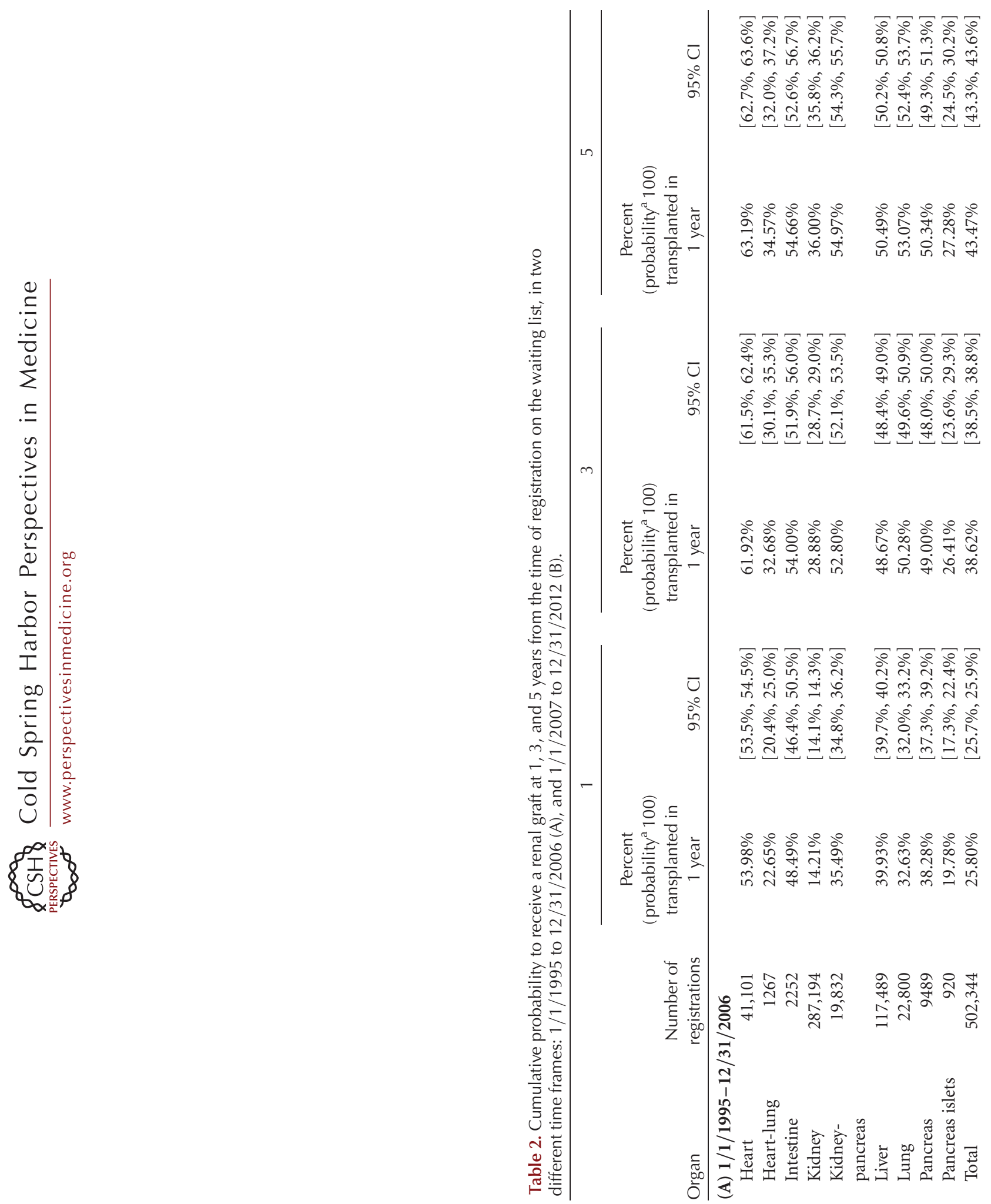
Regenerative Medicine and Transplantation
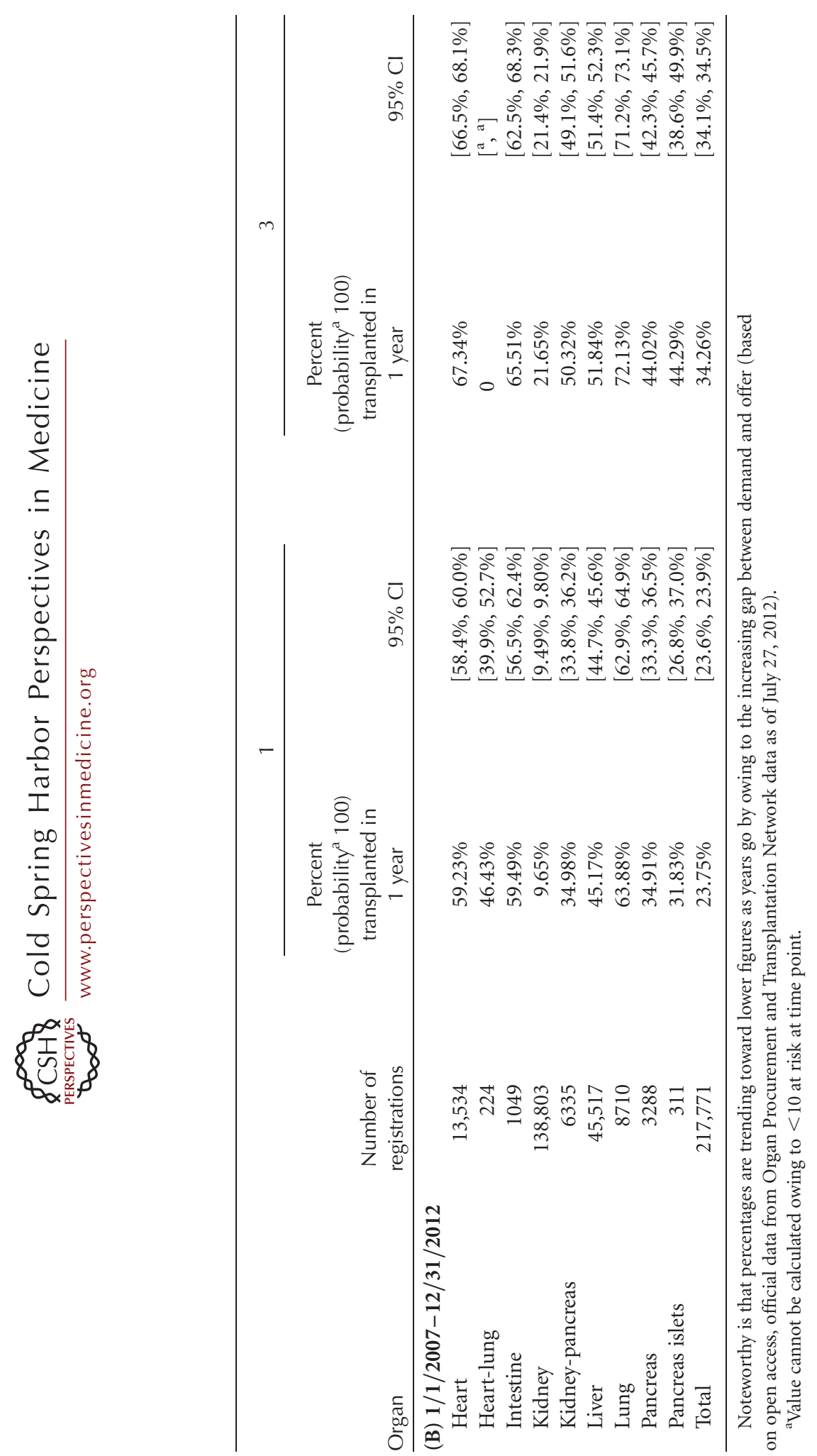
G. Orlando et al.

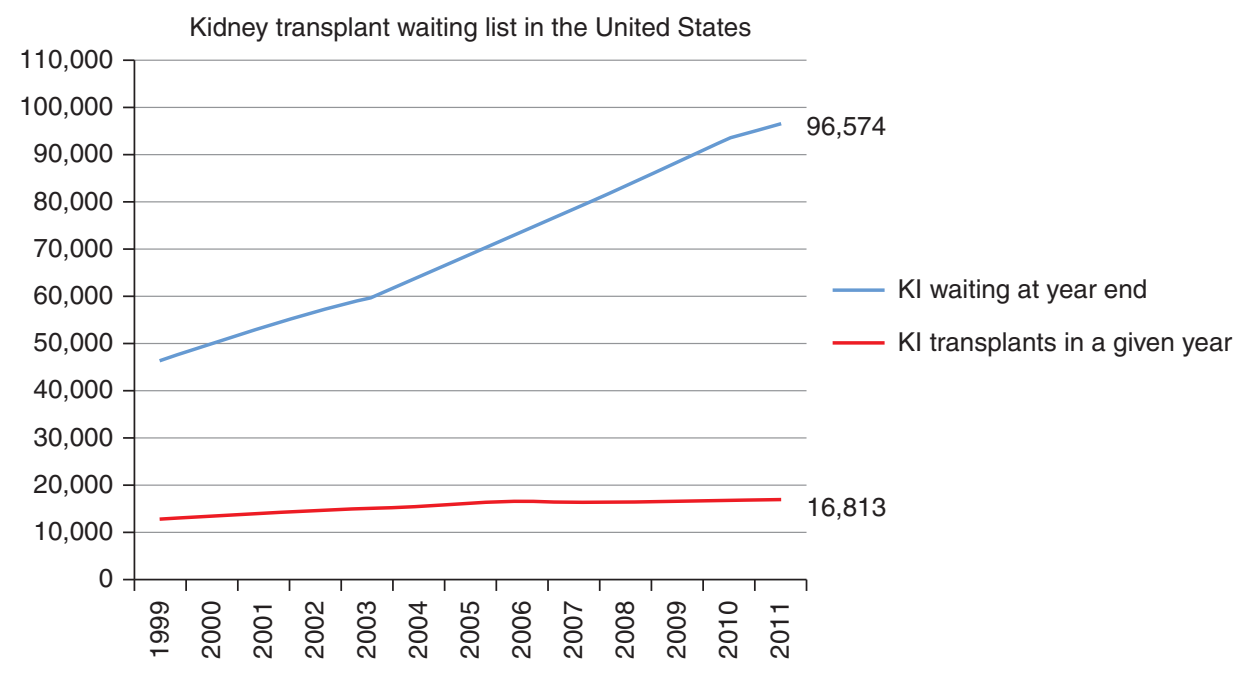

U.S. waiting list and concurrent kidney transplants 1999-2011

Figure 1. Representation of the comparison between the number of renal transplants performed yearly since 1999 and the number of patients on the waiting list for a kidney from a deceased donor. The gap between the two variables is dramatically increasing as a consequence of the constantly escalating number of patients registered on the waiting list and an unprecedented attenuation of the growth of kidney transplantation (based on official, open access data from Organ Procurement and Transplantation Network data as of August 24, 2012).

3 and 5 years to $21.65 \%$ and $36 \%$, respectively (unos.org), a rate that is not sufficient to satisfy the demand for transplantable kidneys. For patients aged 60 or older who are placed on the waiting list, nearly half ( $46 \%)$ will die awaiting a potentially life-saving kidney transplant. Mean annual mortality on the kidney waiting list is $6 \%$ per year, and increases to $10 \%$ in the presence of diabetes. Median waiting times range from 3 to 6 years depending on blood type, degree of sensitization, and geographic region. Even in this case, similar figures can be obtained from data analysis of the European population in which, in $2010,91,798$ patients were affected by endstage renal failure but only 21,740 renal transplants could be performed (www.era-edtareg.org/files/annualreports/pdf/AnnRep2010. pdf). It is critical to point out that the disparity between organ supply and demand is destined to increase because the number of uremic patients is reaching epidemic proportions worldwide as a consequence of widespread chronic noncommunicable diseases such as diabetes and hypertension, as well as infectious diseases and malnutrition in low socioeconomic coun- tries (Meguid et al. 2005). At present, it is estimated that only $6 \%$ of the dialysis population will ever receive a kidney transplant. This data does not leave much to the imagination.

\section{THE PURSUIT OF AN IMMUNOSUPPRESSION-FREE STATE}

The ultimate goal of transplantation should be the achievement of an immunosuppression-free status, in which the recipient of an allograft is not receiving any immunosuppression while enjoying normal graft function (Orlando et al. 2009, 2010a; Orlando 2010). By definition, such an individual should have preserved the ability to mount an immune response to a third party and to infections, and should not present any signs of rejection at any clinical level (physical examination, laboratory or pathology testing, or genomic testing). Therefore, the induction of specific unresponsiveness to alloantigens would render lifelong immunosuppression unnecessary and would ultimately prevent all related complications and abate all costs, while dramatically improving the patient's quality of life. In 
fact, chronic immunosuppression that is required to prevent rejection places patients at risk for infectious and metabolic complications, as well as for malignancies and drug-specific toxicities.

If we remain in the context of kidney transplantation, infections are among the major causes of hospitalization in the first 2 years posttransplant and represent the main cause of hospitalization in the pediatric kidney transplant population (Dharnidharka et al. 2004). Moreover, cardiovascular events (which are related to long-term immunosuppression) represent the major cause of death (Dantal and Soulillou 2005). When compared with an age-matched healthy population, transplant recipients have an increased incidence of cancer, shown by the fact that after 20 years of immunosuppression, $40 \%$ of kidney transplant patients develop cancer and the risk is related to the amount of immunosuppressive drugs received (Dantal et al. 1998). In addition, about 50\% of kidney grafts are lost within 10 years following transplant secondary to chronic allograft nephropathy, a process that depends on a combination of alloantigen-dependent and -independent factors, the latter of which includes the toxic effects of immunosuppression such as nephrotoxicity, hypertension, and hyperlipidemia.

Two more factors have fueled initiatives aiming to achieve immunosuppression-free transplantation. These include the high cost of immunosuppressive drugs and how they affect quality of life. Organ transplantation is one of the most expensive therapies currently available, and has a remarkable impact on hospital and health care systems expenditures. Countries in which the national health services are overburdened by the increasing medical needs of an aging population have to adopt strict cost optimization to limit access and expenses (Filipponi et al. 2003). Given the extremely high cost of lifelong antirejection therapy, a current challenge consists of devising management strategies that lower the expenses of transplantation without having an impact on clinical outcomes. In addition to patient and graft survival rates, it has been shown that improved quality of life is an important outcome measure after organ transplantation in addition to acute rejection and infection rates; these outcomes are important in determining the safety and efficacy of immunosuppressive regimens and function as a guide for other therapeutic choices (Karam et al. 2003). This occurs owing to the fact that patients are now informed about the results and outcomes achieved with transplantation from which they not only expect to be healed, but also achieve similar quality of life as nontransplant individuals. It is important to note that the cost of treatment along with the frequency and dosage of prescribed medications are among the factors that have the most impact on a patient's quality of life, meaning the more drugs and the higher the doses, the lower the perceived quality of life (Galbraith 2004). In addition, patient nonadherence-which is one of the most important determinants of treatment and major causes of organ failure-is significantly influenced by the number of medications as well. Therefore, the optimal immunosuppressive regimen should strive to use the fewest agents at the lowest effective doses to reduce toxicities and costs, but still prevent acute rejection and disease recurrence and maintain graft function while increasing patient satisfaction.

Currently, an immunosuppression-free status can be pursued by either using organs from genetically identical donors or by establishing a state of immunological tolerance. Unfortunately, transplantation among genetically identical individuals is exceptional, whereas true or complete tolerance can only be achieved in a small percentage of liver transplant recipients and remains an elusive goal after transplantation of other organs (Orlando et al. 2009, 2010a; Orlando 2010). After liver transplantation, an immunosuppression-free state can be attempted safely without exposing the patient to any harm, yet the candidate must meet very strict criteria and should have stable graft function and be at least 1 year following transplantation. Therefore, even in the case of liver transplantation, tolerance is never immediate, stable, or durable (Orlando et al. 2011a), and is attainable in only one out of four patients who undergo planned weaning of immunosuppression. When other transplantable organs are considered, the sce- 
nario is even worse. In fact, clinical tolerance has never been reported after intestinal, islet, or whole organ pancreas transplantation, whereas two exceptional cases of patients who developed operational tolerance have been described after lung and heart transplantation (Orlando et al. 2010a). In the case of renal transplantation, the achievement of a permanent and stable immunosuppression-free state is exceptional and all attempts to generate such a tolerant state reported to date have involved complex regimens with nonreproducible results. Overall, tolerogenic strategies are not yet available for daily clinical practice because they are not consistently effective, practical, or safe. Despite significant progress in the field of clinical transplant immunology, the understanding of the immune mechanisms underlying tolerance remains inadequate.

Ideally, and as anticipated above, tolerance should be immediate, stable, and durable. It should develop immediately after reperfusion without requiring any sort of induction or maintenance immunosuppression. It should be refractory to all insults that may alter the balance between self and nonself (stable). Finally, it should last as long as the graft itself (durable). Although none of the immunology-based presumed tolerogenic strategies have ever been able to achieve these goals, regenerative medicine technologies have permitted the bioengineering of relatively simple, hollow organs from a patient's own cells. These organs have been implanted in more than 160 patients suffering from different medical conditions without the need for antirejection treatment (Romagnoli et al. 1990; Pellegrini et al. 1997; Quarto et al. 2001; Shinoka et al. 2001; Warnke et al. 2004; Atala et al. 2006; Macchiarini et al. 2008; McAllister et al. 2009; Mertsching et al. 2009; Baiguera et al. 2010; Hibino et al. 2010; Rama et al. 2010; Junglebuth et al. 2011; Elliott et al. 2012; Olausson et al. 2012; Orlando et al. 2012b). Importantly, these figures far exceed the number of organ recipients who have been successfully weaned off all immunosuppression in the immediate postoperative period. Although the production of more complex modular organs of transplant interest-namely, kidney, liver, heart, lung, pancreas or islet, and intestinehave not been documented, it is incontrovertible that regenerative medicine is opening an exciting arena for investigations that may tremendously impact organ transplantation.

\section{HOLLOW VERSUS COMPLEX MODULAR ORGANS}

To date, progress in regenerative medicine has been defined by methods and technologies that have led to the production and implantation of hollow organs, which-from a bioengineering perspective-are less complex than the so-called complex modular organs. These latter are organs organized in functioning units referred to as modules that require reconnection to the vascular system of the recipient at the time of implantation to be viable. The heart, liver, lung, pancreas, and intestine are complex modular organs. On the other hand, hollow organs are either conduits (vessels, upper airways, urethras) or reservoirs (bladders), which theoretically are able to exert their function regardless of a direct reconnection to the recipient's bloodstream.

It is important to emphasize that traditional anatomy defines as hollow organs any "visceral organ that is a hollow tube or pouch (as the stomach or intestine) or includes a cavity (as the heart or urinary bladder)" (en.wikipedia. org/wiki/Organ_(28anatomy)). Nevertheless, from a regenerative medicine perspective, the definition is based on function rather than shape, and consequently intestine and heart are not considered hollow organs but rather complex modular organs. In fact, although the liver, kidney, and pancreas are intuitively considered to be complex modular organs, the heart and digestive tract may be referred to as hollow organs because of the fact that they clearly include cavities (in the case of the heart) or consist of a hollow tube (the intestine). Instead, in this specific context, myocardiocytes themselves and villi are considered the modules (namely, the functioning units) of heart and intestine, respectively. Vessels, bladders, upper airways, and urethras comply with the traditional definition of hollow organs.

Notably, all the bioengineered organs that, to date, have been reported to be implanted in 
humans were hollow organs, whereas the bioengineering of cardiac, hepatic, renal, pancreatic, and intestinal organoids is still far from the realm of possibility. The main technology that is currently being implemented for organ bioengineering consists of seeding cells on supporting scaffolding materials. We refer to this method as cell-scaffold technology, which is based on the idea-actually, on the dogma!-that cells require a supporting structure (which in vivo is represented by the extracellular matrix) to grow, expand, and exert their function. This notion is not new but has circulated for decades (Bissell et al. 1982). A paradigmatic example of the essential role of this interplay between cells and extracellular matrix is offered by clinical whole pancreas transplantation versus transplantation of pancreatic islets. Whole pancreas transplantation and islet transplantation are currently the only known therapies that reliably establish a long-term stable euglycemic state (Orlando et al. 2010b). Following these types of transplant, endogenous insulin secretion in response to normal feedback controls is restored and glycosylated hemoglobin levels normalize in the absence of the need for exogenous insulin therapy. However, if we compare the mid- and long-term outcome of these two different types of $\beta$-cell replacement therapies, whole pancreas transplantation overrides islet transplantation. In fact, despite a significant improvement in the overall results of islet transplantation recently reported by the Collaborative Islet Transplant Registry (CITR) (Barton et al. 2012), insulin independence rates, C-peptide and HbAlc serum levels, and long-term resolution of severe hypoglycemia recorded after islet transplantation remain inferior to whole pancreas transplantation, which remains the gold standard for diabetes treatment. These findings have been attributed to several factors, the most important of which are cold ischemia-derived stress and rejection. This notwithstanding, from a regenerative medicine (RM) perspective, the explanation is far more simple and lies in the fact that when islets_-namely, clusters of cells_-are removed from their microenvironment and therefore not supported by their natural supporting scaffold, they undergo tremendous stress that dramatically harms their welfare and viability.

Cellular material used in cell-scaffold technology may include adult cells, different types of progenitor cells per se, or progenitor cells that can be induced to differentiate into specific adult cell types. The scaffolds used may be either synthetic or natural, the latter being obtained via detergent-based decellularization of organs from animals or humans, a method that consistently allows for the complete clearance of the cellular compartment of almost any organ on any scale. Scaffolds obtained from innate organs seem to offer the best chances for success as they are naturally biocompatible and bioactive, while being relatively inexpensive and easy to access. They represent a biochemically, geometrically, and spatially ideal platform for bioengineering investigations, because they have both basic components (proteins and polysaccharides) and matrix-bound growth factors and cytokines preserved (Wang et al. 2011), they retain an intact and patent vasculature whichwhen implanted in vivo-sustains the physiologic blood pressure (Orlando et al. 2012a), and are able to drive differentiation of progenitor cells into an organ-specific phenotype (Bissell et al. 1982; Chung et al. 2005; Ross et al. 2009; $\mathrm{Ng}$ et al. 2011).

Although the above-mentioned hollow organs that have already been implanted in humans were produced mainly from synthetic scaffolds, natural scaffolds obtained from animals of various sizes and species have been used as a platform for cardiac, liver, pancreas, intestine, and renal bioengineering with some promising results and achievements. In the case of hollow organs, autologous cells were collected from the patients and expanded in vitro. In some cases, stem cells were isolated and then spontaneously differentiated into specific cell types before being seeded on supporting scaffolds (Junglebuth et al. 2011; Elliott et al. 2012). Afterward, the soobtained cellular constructs were either allowed to mature in bioreactors or were implanted immediately after seeding without undergoing any maturation phase (Elliott et al. 2012). As such, cell-scaffold technology has made it possible to manufacture and implant relatively simple 


\section{G. Orlando et al.}

structures such as vessels, segments of upper airways, urethras, and neo-urinary conducts. However, current reports refer to very small series with short follow-up and insufficient discussion of the complications and limitations that may occur over time.

\section{PLAYGROUNDS FOR FUTURE INVESTIGATIONS}

\section{Developmental and Evolutionary Biology}

It seems apparent that the sequence of events represented by the seeding of cells on supporting scaffolding material $\rightarrow$ cell attachment to the extracellular matrix $\rightarrow$ growth $\rightarrow$ expansion followed by the so-called maturation phase that may take place either in bioreactors or in vivo, is not sufficient to allow effective and robust maturation of the new organoid, which is the sine qua non for the successful integration of the new construct with what will be its new environment following implantation. Theoretically what is expected to occur during the abovementioned sequence of steps is the dynamic recapitulation of all events occurring in utero under physiological conditions during organ ontogenesis. Unfortunately, most of these events remain unknown and the mechanisms underlying them, indefinite. Therefore, in-depth knowledge of the mechanisms through which organs develop is essential in organ bioengineering, as well as the acquisition of information on how cells, tissues, and organs respond to injury and implement repair and healing strategies.

It should be emphasized that an evolutionary approach to organ bioengineering and regeneration is needed as it is complementary to a genuinely developmental approach. We believe that investigators in the field should consider as a priority the understanding of why mammals, during phylogenesis, have lost the ability to regenerate themselves, a function that instead characterizes virtually all simple organisms of the animal and plant kingdoms. In fact, the notion that the more simply organized animals are capable of regenerating larger parts of their bodies when compared with animals with higher organization and complexity like mammals has been well known for almost a century, as it was formulated for the first time by the Russian embryologist P.P. Ivanov in 1937 (Fig. 2) (Ivanov 1937). If we take into account the fact that mammals in utero show formidable regenerative capacities that are lost after birth, we then infer that mammals — and so humans - do have innate regenerative abilities that nevertheless, for reasons that remain dramatically mysterious, are disabled or at least dramatically impaired ex utero. We therefore believe that the greatest challenge for RM researchers is to understand why and how this happens.

\section{Bioreactors}

Bioreactors represent a dynamic, controllable and reproducible culture environment designed to support the regeneration process and from which the bioengineered tissue/organ can be harvested for analysis or implantation. Bioreactors are devices that facilitate, monitor, and control biological, biochemical, and biophysical processes, and allow uniform scaffold cell distribution, ideal nutrient supply and waste removal, as well as hydrodynamic shear stress (Baiguera et al. 2010; Rauh et al. 2011). Shear stress is produced by forces inherent to the bioreactor-like rotation and other factors essential for tissue development, because it contributes to supporting metabolic activity and differentiation. Theoretically, bioreactors mimic in vivo conditions (temperature, oxygen concentration, $\mathrm{pH}$, nutrient concentration, and biochemical and mechanical stimuli), which are the environment where the maturation phase follows cell seeding of the scaffold.

Unfortunately, present technology does not seem to produce adequate bioreactors. The recent report from the Great Ormond Street Hospital, London, UK, where a newly bioengineered segment of upper airways (Elliott et al. 2012) was implanted immediately after manufacturing (without undergoing any maturation phase) questions the quality and efficacy of currently available bioreactors. In fact, in all previous cases of implantation of bioengineered segments of the upper airways, the new construct was allowed to mature in a bioreactor before 


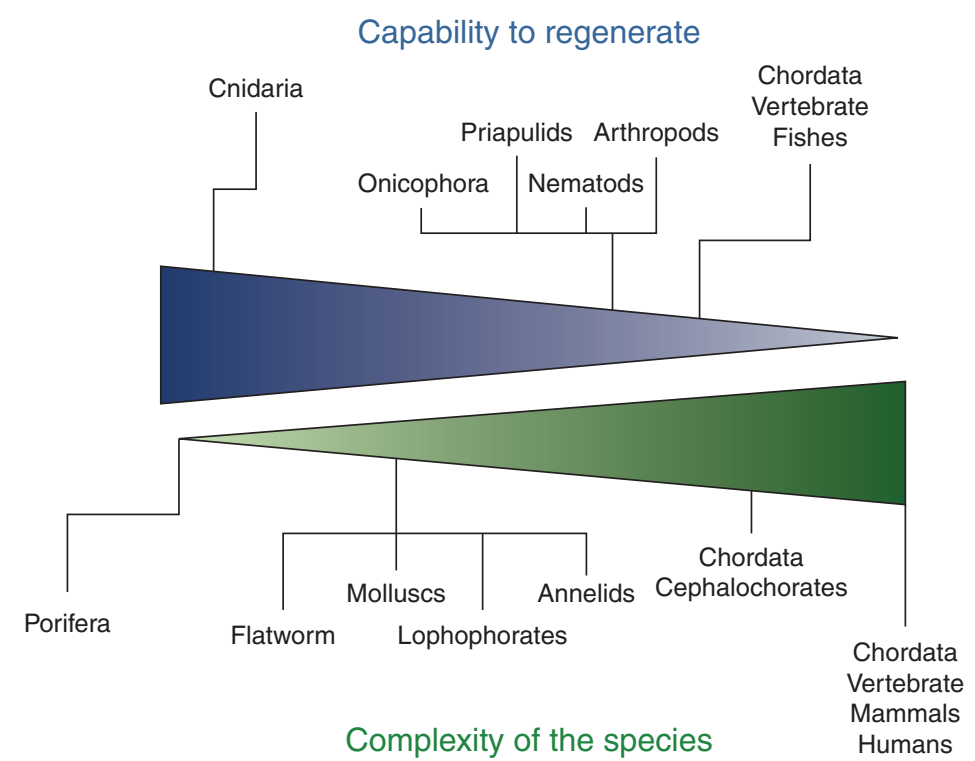

Figure 2. The ability to regenerate inversely proportional to the degree of complexity of a species. Phylum Chordata are on the extreme segment of the spectrum, yet some vertebrate species like zebrafish have maintained the capacity to fully regenerate organs after amputation and so represent a formidable experimental model for organ bioengineering and regeneration investigations. Humans are instead at the very end of the spectrum.

implantation. Seeding techniques, types and numbers of cells, reproduction of adequate biophysical forces mimicking those physiologically occurring in vivo, and composition and architecture of biomaterials are key factors for success in organ bioengineering and regeneration, and the lack or impairment of just one of these factors may lead per se to failure, regardless of whether all other factors are appropriate.

\section{Vascularization}

Importantly, all bioengineered constructs reported to date have been implanted without being reconnected to the systemic vascular system, thereby exposing the new organ to ischemia and ultimately to the risk of graft failure. All organs require a vascular supply, whereas it is well known that cells can survive only within an area approximately $1-3 \mathrm{~mm}$ away from a source of nutrients and oxygen (Folkman and Hochberg 1973). Therefore, the pivotal role of the reconnection of the vascular network to the systemic bloodstream to allow adequate oxygen and nutrients supply cannot be underestimated, unless the size of the body part in question is smaller than $0.3 \mathrm{~cm}$. Interestingly, Macchiarini's group reported the occurrence of a ventral collapse of the most proximal $1 \mathrm{~cm}$ of the graft 8 months after the implantation of his first bioengineered trachea. Despite the investigators' speculation that this complication was owing to the pulsatile compression from the aortic arch superiorly and to the migration of the stem-cell-derived chondrocytes into the endoluminal surface of the graft, common sense suggests that it may simply have been caused by ischemia as the new organ did not have a vascular pedicle and was not reconnected to systemic circulation. For complex modular organs like kidneys, livers, and hearts, there is no question that vascular pedicles will have to be reconnected to the systemic circulation. For this reason, natural extracellular matrix scaffolds obtained from the decellularization of organs derived from animals and humans represent the ideal platform owing to their ability to maintain a well-preserved framework of their intrinsic vascular tree. In the case of renal extracellular matrix scaffolds obtained from kidneys discarded 
G. Orlando et al.

from human transplantation, or from pigs, the injection of regular contrast media within the renal artery depicts an intact vascular network that retains the hierarchical branching structures. Contrast media flows progressively from larger vessels to smaller capillaries to eventually drain out through the stump of the renal vein, without extravasation within the scaffold parenchyma (Orlando et al. 2012a).

\section{RM AS THE NEW HOLY GRAIL FOR ORGAN TRANSPLANTATION}

The Holy Grail is a sacred object found in literature and Christian traditions most often identified as a dish, plate, or cup allegedly used by Jesus at the Last Supper (en.wikipedia.org/ wiki/Holy_Grail) (G Orlando, unpubl.). According to the legend, the Holy Grail was used by Joseph of Arimathea to collect Jesus' blood and sweat at the time of Jesus' crucifixion. After Christ's death, Joseph was imprisoned in a rock tomb and left to starve, nevertheless he survived because he could hide and bring with him the Holy Grail that gave him energy. Once out of prison, Joseph was sustained for several years by the power of the Grail, which provided him with fresh food and drink every morning (www.britannia.com/history/arthur/grail). In the Christian tradition, the Holy Grail is believed to possess miraculous powers and has therefore been the object of quest and intense research for centuries. However, no one has ever found where it has been carefully guarded, thus questioning whether the Holy Grail ever existed or whether it was a mere product of human fantasy.

In the literature and common language, the metaphor of the Holy Grail is often used to describe an exceptionally rare object or an ultimate, near-unattainable goal. In organ transplantation, the establishment of an immunosuppression-free state (otherwise said, tolerance) has represented the Holy Grail since the time when transplant investigators understood that the tool that allowed organ transplantation to become a formidable clinical treatment—namely, immunosuppression-should be considered also as our main foe as it is the primary determinant of patient mortality and morbidity from the sec- ond year posttransplant and beyond. Although tolerance has been the primary end point of innumerable investigations that have required massive investments since the early pioneering years, to date it remains an elusive goal. As we explained above, immediate, stable, robust, and durable tolerance cannot be obtained with available technology and the different strategies attempted to date are not yet reproducibly safe, effective, or easily applicable to large numbers of patients.

\section{CONCLUSIVE REMARKS}

Recent groundbreaking advances in organ bioengineering and regeneration have shown the immense potential that RM holds to change transplantation. It is now clear that the legacy that Alexis Carrel has left for the present and future generations of transplant and RM investigators is much richer than we thought and is not just about transplantation but also about RM. These two fields share a common ancestry and are destined to interdigitate in the future. Although RM has shown to the transplant field its tremendous potential, transplantation is destined to synergize with RM and foster further progress probably more than either field can achieve individually. The reason for this lies in the fact that organ bioengineering and regeneration technologies hold the promise to meet at the same time the two most urgent needs of organ transplantation, namely, the identification of a new, potentially inexhaustible source of organs and immunosuppression-free transplantation. The years ahead of us will be extraordinarily exciting and may rival the early pioneering years of transplantation.

\section{REFERENCES}

Atala A, Bauer SB, Soker S, Yoo JJ, Retik AB. 2006. Tissueengineered autologous bladders for patients needing cystoplasty. Lancet 367: 1241-1246.

Badylak SF, Weiss DJ, Caplan A, Macchiarini P. 2012. Engineered whole organs and complex tissues. Lancet 379: 943-952.

Baiguera S, Birchall MA, Macchiarini P. 2010. Tissue-engineered tracheal transplantation. Transplantation 89: $485-$ 491. 
Baptista PM, Siddiqui MM, Lozier G, Rodriguez SR, Atala A, Soker S. 2011. The use of whole organ decellularization for the generation of a vascularized liver organoid. Hepatology 53: 604-617.

Barakat O, Abbasi S, Rodriguez G, Rios J, Wood RP, Ozaki C, Holley LS, Gauthier PK. 2012. Use of decellularized porcine liver for engineering humanized liver organ. J Surg Res 173: e11-e25.

Barton FB, Rickels MR, Alejandro R, Hering BJ, Wease S, Naziruddin B, Oberholzer J, Odorico JS, Garfinkel MR, Levy M, et al. 2012. Improvement in outcomes of clinical islet transplantation: 1999-2010. Diabetes Care 35: $1436-1445$.

Bissell MJ, Hall HG, Parry G. 1982. How does the extracellular matrix direct gene expression? J Theor Biol 99: 3168.

Chung SY, Krivorov NP, Rausei V, Thomas L, Frantzen M, Landsittel D, Kang YM, Chon CH, Ng CS, Fuchs GJ. 2005. Bladder reconstitution with bone marrow derived stem cells seeded on small intestinal submucosa improves morphological and molecular composition. J Urol 174: 353-359.

Dantal J, Soulillou JP. 2005. Immunosuppressive drugs and the risk of cancer after organ transplantation. NEngJ Med 352: $1371-1373$.

Dantal J, Hourmant M, Cantarovich D, Giral M, Blancho G, Dreno B, Soulillou JP. 1998. Effect of long-term immunosuppression in kidney-graft recipients on cancer incidence: Randomised comparison of two cyclosporin regimens. Lancet 351: 623-628.

Dharnidharka VR, Stablein DM, Harmon WE. 2004. Posttransplant infections now exceed acute rejection as cause for hospitalization: A report of the NAPRTCS. Am J Transpl 4: 384-389.

Elliott MJ, De Coppi P, Speggiorin S, Roebuck D, Butler CR, Samuel E, Crowley C, McLaren C, Fierens A, Vondrys D, et al. 2012. Stem-cell-based, tissue engineered tracheal replacement in a child: A 2-year follow-up study. Lancet 380: 994-1000.

Filipponi F, Pisati R, Cavicchini G, Ulivieri MI, Ferrara R, Mosca F. 2003. Cost and outcome analysis and cost determinants of liver transplantation in a European national health service hospital. Transplantation 275: 17311736 .

Folkman J, Hochberg M. 1973. Self-regulation of growth in three dimensions. J Exp Med 138: 745-753.

Galbraith CA, Hathaway D. 2004. Long-term effects of transplantation on quality of life. Transplantation 77: S84-S87.

Hammond JS, Gilbert TW, Howard D, Zaitoun A, Michalopoulos G, Shakesheff KM, Beckingham IJ, Badylak SF 2011. Scaffolds containing growth factors and extracellular matrix induce hepatocyte proliferation and cell migration in normal and regenerating rat liver. J Hepatol 54: 279-287.

Hata T, Uemoto S, Fujimoto Y, Murakami T, Tateno C, Yoshizato K, Kobayashi E. 2012. Transplantation of engineered chimeric liver with autologous hepatocytes and xenobiotic scaffold. Ann Surg 257: 542-547.

Hibino N, McGillicuddy E, Matsumura G, Ichihara Y, Naito Y, Breuer C, Shinoka T. 2010. Late-term results of tissue-
Regenerative Medicine and Transplantation

engineered vascular grafts in humans. $J$ Thorac Cardiovasc Surg 139: 431-436.

Ivanov PP. 1937. Obshchaia $i$ sravnitel'naia embriologiia. Moscow-Leningrad.

Jungebluth P, Alici E, Baiguera S, Le Blanc K, Blomberg P, Bozóky B, Crowley C, Einarsson O, Grinnemo KH, Gudbjartsson T, et al. 2011. Tracheobronchial transplantation with a stem-cell-seeded bioartificial nanocomposite: A proof-of-concept study. Lancet 378: 1997-2004.

Karam VH, Gasquet I, Delvart V, Hiesse C, Dorent R, Danet C, Samuel D, Charpentier B, Gandjbakhch I, Bismuth H, et al. 2003. Quality of life in adult survivors beyond 10 years after liver, kidney, and heart transplantation. Transplantation 76: 1699-1704.

Macchiarini P, Jungebluth P, Go T, Asnaghi MA, Rees LE, Cogan TA, Dodson A, Martorell J, Bellini S, Parnigotto PP, et al. 2008. Clinical transplantation of a tissue-engineered airway. Lancet 372: 2023-2030.

McAllister TN, Maruszewski M, Garrido SA, Wystrychowski W, Dusserre N, Marini A, Zagalski K, Fiorillo A, Avila H, Manglano X, et al. 2009. Effectiveness of haemodialysis access with an autologous tissue-engineered vascular graft: A multicentre cohort study. Lancet 373: 1440 1446.

Meguid El, Nahas A, Bello AK. 2005. Chronic kidney disease: The global challenge. Lancet 365: 331-334.

Mertsching H, Schanz J, Steger V, Schandar M, Schenk M, Hansmann J, Dally I, Friedel G, Walles T. 2009. Generation and transplantation of an autologous vascularized bioartificial human tissue. Transplantation 88: 203-210.

Ng SL, Narayanan K, Gao S, Wan AC. 2011. Lineage restricted progenitors for the repopulation of decellularized heart. Biomaterials 32: 7571-7580.

Olausson M, Patil PB, Kuna VK, Chougule P, Hernandez N, Methe K, Kullberg-Lindh C, Borg H, Ejnell H, SumitranHolgersson S. 2012. Transplantation of an allogeneic vein bioengineered with autologous stem cells: A proof-ofconcept study. Lancet 380: 230-237.

Orlando G. 2010. Finding the right time for weaning off immunosuppression in solid organ transplant recipients. Expert Rev Clin Immunol 6: 879-892.

Orlando G, Soker S, Wood K. 2009. Clinical operational tolerance after liver transplantation. J Hepatol 50: 1247-1257.

Orlando G, Hematti P, Stratta RJ, Burke GW, Di Cocco P, Pisani F, Soker S, Wood KJ. 2010a. Clinical operational tolerance after renal transplantation: Current status and future challenges. Ann Surg 252: 913-926.

Orlando G, Stratta RJ, Light J. 2010b. Pancreas transplantation for type 2 diabetes mellitus. Curr Opin Organ Transplant 16: $110-115$.

Orlando G, Wood KJ, Soker S, Stratta RJ. 2011a. How regenerative medicine may contribute to the achievement of an immunosuppression-free state. Transplantation 92: e36-e38.

Orlando G, Wood KJ, Stratta RJ, Yoo J, Atala A, Soker S. 2011b. Regenerative medicine and organ transplantation: Past, present and future. Transplantation 91: 1310-1317.

Orlando G, Farney A, Sullivan DC, Abouschwareb T, Iskandar S, Wood KJ, Atala A, Stratta RJ, Yoo JJ, Soker S. 2012a. Production and implantation of renal extracellular ma- 
G. Orlando et al.

trix scaffolds from porcine kidneys as a platform for renal bioengineering investigations. Ann Surg 256: $363-$ 370.

Orlando G, Wood KJ, De Coppi P, Baptista PM, Binder KW, Bitar KN, Breuer C, Burnett L, Christ G, Farney A, et al. 2012b. Regenerative medicine as applied to general surgery. Ann Surg 255: 867-880.

Ott HC, Matthiesen TS, Goh SK, Black LD, Kren SM, Netoff TI, Taylor DA. 2008. Perfusion-decellularized matrix: Using nature's platform to engineer a bioartificial heart. Nat Med 14: 213-221.

Ott HC, Clippinger B, Conrad C, Schuetz C, Pomerantseva I, Ikonomou L, Kotton D, Vacanti JP. 2010. Regeneration and orthotopic transplantation of a bioartificial lung. Nat Med 16: 927-933.

Pellegrini G, Traverso CE, Franzi AT, Zingirian M, Cancedda R, De Luca M. 1997. Long-term restoration of damaged corneal surfaces with autologous cultivated corneal epithelium. Lancet 349: 990-993.

Petersen TH, Calle EA, Zhao L, Lee EJ, Gui L, Raredon MB, Gavrilov K, Yi T, Zhuang ZW, Breuer C, et al. 2010. Tissue-engineered lungs for in vivo implantation. Science 29: $538-541$.

Quarto R, Mastrogiacomo M, Cancedda R, Kutepov SM, Mukhachev V, Lavroukov A, Kon E, Marcacci M. 2001. Repair of large bone defects with the use of autologous bone marrow stromal cells. $N$ Engl J Med 344: 385-386.

Rama P, Matuska S, Paganoni G, Spinelli A, De Luca M, Pellegrini G. 2010. Limbal stem-cell therapy and longterm corneal regeneration. N Engl J Med 363: 147-155.

Rauh J, Milan F, Günther KP, Stiehler M. 2011. Bioreactor systems for bone tissue engineering. Tissue Eng Part B Rev 17: $263-280$.

Romagnoli G, De Luca M, Faranda F, Bandelloni R, Franzi AT, Cataliotti F, Cancedda R. 1990. Treatment of posterior hypospadias by the autologous graft of cultured urethral epithelium. N Engl J Med 323: 527-530.
Ross EA, Williams MJ, Hamazaki T, Terada N, Clapp WL, Adin C, Ellison GW, Jorgensen M, Batich CD. 2009. Embryonic stem cells proliferate and differentiate when seeded into kidney scaffolds. J Am Soc Nephrol 20: 23382347.

Shinoka T, Imai Y, Ikada Y. 2001. Transplantation of a tissueengineered pulmonary artery. $N$ Engl J Med 344: $532-$ 533.

Soto-Gutierrez A, Zhang L, Medberry C, Fukumitsu K, Faulk D, Jiang H, Reing J, Gramignoli R, Komori J, Ross M, et al. 2011. A whole-organ regenerative medicine approach for liver replacement. Tissue Eng Part C Methods 17: 677-686.

Uygun BE, Soto-Gutierrez A, Yagi H, Izamis ML, Guzzardi MA, Shulman C, Milwid J, Kobayashi N, Tilles A, Berthiaume F, et al. 2010. Organ reengineering through development of a transplantable recellularized liver graft using decellularized liver matrix. Nat Med 16: 814-820.

Wainwright JM, Czajka CA, Patel UB, Freytes DO, Tobita K, Gilbert TW, Badylak SE. 2010. Preparation of cardiac extracellular matrix from an intact porcine heart. Tissue Eng Part C Methods 16: 525-532.

Wang Y, Cui CB, Yamauchi M, Miguez P, Roach M, Malavarca R, Costello MJ, Cardinale V, Wauthier E, Barbier C, et al. 2011. Lineage restriction of human hepatic stem cells to mature fates is made efficient by tissue-specific biomatrix scaffolds. Hepatology 53: 293-305.

Warnke PH, Springer IN, Wiltfang J, Acil Y, Eufinger H, Wehmöller M, Russo PA, Bolte H, Sherry E, Behrens E, et al. 2004. Growth and transplantation of a custom vascularised bone graft in a man. Lancet 364: 766-770.

Yagi H, Fukumitsu K, Fukuda K, Kitago M, Shinoda M, Obara H, Itano O, Kawachi S, Tanabe M, Coudriet GM, et al. 2012. Human-scale whole-organ bioengineering for liver transplantation: A regenerative medicine approach. Cell Transplant 22: 231-242. 


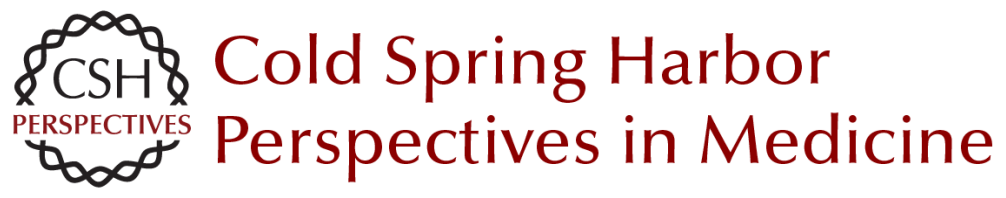

\section{Will Regenerative Medicine Replace Transplantation?}

Giuseppe Orlando, Shay Soker, Robert J. Stratta and Anthony Atala

Cold Spring Harb Perspect Med 2013; doi: 10.1101/cshperspect.a015693

Subject Collection Transplantation

Heart Transplantation: Challenges Facing the Field

Makoto Tonsho, Sebastian Michel, Zain Ahmed, et al.

Bioethics of Organ Transplantation Arthur Caplan

Overview of Clinical Lung Transplantation Jonathan C. Yeung and Shaf Keshavjee

Immunological Challenges and Therapies in

Xenotransplantation Marta Vadori and Emanuele Cozzi

Clinical Aspects: Focusing on Key Unique Organ-Specific Issues of Renal Transplantation Sindhu Chandran and Flavio Vincenti

T-Cell Costimulatory Blockade in Organ

Transplantation Jonathan S. Maltzman and Laurence A. Turka

Regulatory T-Cell Therapy in Transplantation: Moving to the Clinic Qizhi Tang and Jeffrey A. Bluestone

Opportunistic Infections--Coming to the Limits of Immunosuppression?

Jay A. Fishman
Overview of the Indications and Contraindications for Liver Transplantation

Stefan Farkas, Christina Hackl and Hans Jürgen Schlitt

Facial and Hand Allotransplantation Bohdan Pomahac, Ryan M. Gobble and Stefan Schneeberger

Induction of Tolerance through Mixed Chimerism David H. Sachs, Tatsuo Kawai and Megan Sykes

Pancreas Transplantation: Solid Organ and Islet Shruti Mittal, Paul Johnson and Peter Friend

Tolerance--Is It Worth It? Erik B. Finger, Terry B. Strom and Arthur J. Matas

Lessons and Limits of Mouse Models Anita S. Chong, Maria-Luisa Alegre, Michelle L. Miller, et al.

Effector Mechanisms of Rejection Aurélie Moreau, Emilie Varey, Ignacio Anegon, et al.

The Innate Immune System and Transplantation Conrad A. Farrar, Jerzy W. Kupiec-Weglinski and Steven H. Sacks

For additional articles in this collection, see http://perspectivesinmedicine.cshlp.org/cgi/collection/ 